\title{
Development of swimming abilities in reef fish larvae
}

\author{
Rebecca Fisher*, David R. Bellwood, Suresh D. Job \\ Department of Marine Biology, James Cook University, Townsville, Queensland 4811, Australia
}

\begin{abstract}
Recent studies have revealed that reef fish larvae have excellent sustained swimming capabilities and considerable potential for modifying their dispersal patterns by active swimming. However, these studies concentrate solely on the late pelagic phase. We examined the development of swimming abilities from hatching through to settlement in 3 reef fish species (Pomacentrus amboinensis, Sphaeramia nematoptera, Amphiprion melanopus). Larval rearing provided larvae at all stages of development. Experiments were conducted in flow chambers designed for measuring the critical and sustained swimming capability of young larvae. In all 3 species, critical swimming ability increased steadily with age, size, relative propulsive area and developmental stage of the larvae. In contrast, sustained swimming ability showed a marked inflection during development. Differences among species throughout development appear to reflect variations in the developmental patterns of the 3 species. Propulsive area was highly correlated with swimming ability and may prove useful for estimating swimming capabilities among species. The results suggest that some species have the potential to actively modify their dispersal patterns from an early age.
\end{abstract}

KEY WORDS: Larvae $\cdot$ Swimming $\cdot$ Dispersal $\cdot$ Coral reef fish $\cdot$ Development $\cdot$ Morphology

Resale or republication not permitted without written consent of the publisher

\section{INTRODUCTION}

Coral reef fishes are generally sedentary as adults, with most possessing a dispersive larval phase. This phase lasts for several days or weeks, and during this time they may travel considerable distances. The distribution and abundance of reef fishes is significantly influenced by the dispersal of this planktonic larval stage (Doherty 1991). Knowledge of the extent of larval dispersal among reefs is an essential prerequisite for understanding reef-community dynamics and management (Williams et al. 1984). There has been considerable debate about the relative importance of active behaviour in determining dispersal and distribution patterns of reef fish larvae. The traditional view, which is still maintained by some authors, is that fish larvae have very little behavioural influence over their dispersal patterns and that currents are responsible for the dispersal of larvae to and from reefs (e.g. Roberts

*E-mail: rebecca.fisher@jcu.edu.au
1997). Other workers, however, have suggested that larval behaviour, including vertical and horizontal movement, may influence dispersal patterns (e.g. Cowen et al. 1993, Leis et al. 1996, Stobutzki \& Bellwood 1997).

Recent work has shown that settlement-stage larval reef fishes have considerable swimming abilities over both short-term and prolonged periods. Using a current flume, Stobutzki \& Bellwood (1994) showed that the short-duration swimming speeds of larvae are relatively high, Pomacentrus amboinensis, for example averaging $43.7 \mathrm{~cm} \mathrm{~s}^{-1}$, or approx. 40 body lengths (BL) $\mathrm{s}^{-1}$. Leis et al. (1996) and Leis \& Carson-Ewart (1997) also recorded high swimming speeds, with capturerelease methods recording speeds of $>60 \mathrm{~cm} \mathrm{~s}^{-1}$ for reef fish larvae in the field. These speeds were maintained for several minutes. The sustained swimming abilities of many species were also remarkable. Stobutzki \& Bellwood (1997) recorded some species swimming over $100 \mathrm{~km}$ in a single bout, lasting up to $10 \mathrm{~d}$, at a speed of $13.5 \mathrm{~cm} \mathrm{~s}^{-1}$. These studies describe different measures of swimming ability. The methods employed 
by Stobutzki \& Bellwood provide data on endurance swimming which represents a maximal performance measure of maintained swimming ability. In comparison, the observations of Leis et al. were based in the field with unrestrained larvae, the larvae selecting their swimming speed over relatively short distances. Leis \& Stobutzki (1997) suggested that similarities in the results of the 2 measures indicates that they provide comparable measures of overall abilities. Methodological differences notwithstanding, both approaches have shown that larval fish are capable of considerable horizontal movement.

The abilities of larval fishes to influence their dispersal remains a controversial topic and an area of considerable debate (Roberts 1997, 1998, Bellwood et al. 1998, Sale \& Cowen 1998). While many authors admit that larval behaviour may be important (reviewed by Leis 1991a), few have considered these abilities in the theories and models put forward. Several authors have attempted to explain distribution patterns without considering active movement of larvae (Booth \& Baretta 1994, Roberts 1997). In such cases, it has been assumed that there is no development of swimming ability throughout the larval period. The results of previous studies have clearly demonstrated that this assumption is not valid (Leis \& Carson-Ewart 1997, Stobutzki \& Bellwood 1997). An alternative assumption that has been made is that swimming ability develops rapidly immediately prior to the late-pelagic phase and that this ability is used to move towards reefs at the time of settlement (Wolanski et al. 1997). Such models attempting to include larval behaviour have been limited by the lack of knowledge of swimming abilities in younger larvae. The larvae used in the studies by Stobutzki \& Bellwood (1994, 1997), Leis et al. (1996), Leis \& Carson-Ewart (1997) and Stobutzki (1998) were all caught in light traps and represent late pelagic-stage larvae (Choat et al. 1993). If swimming ability develops earlier in the larval period, then the potential for horizontal swimming to modify dispersal patterns will be greatly underestimated in these dispersal models.

Before we can understand the potential importance of active swimming in larval reef-fish dispersal, we need to determine the swimming ability of different species of reef fishes throughout the entire larval period, rather than just the late-pelagic stage. Investigations into the abilities of younger stages of larval reef fishes has been limited by difficulties in obtaining live individuals in the field in good condition. Larval rearing techniques, however, provide a means of determining the biological capabilities of larval fishes throughout development. By hatching and rearing larvae under controlled conditions, it is possible to obtain live specimens of known age and parentage, in good condition, at all developmental stages. Using captive rearing techniques, the aim of this study was to determine how swimming ability develops with age for several reef fish species. The specific questions to be addressed were: (1) How do critical and sustained swimming ability vary among species during larval development and (2) To what extent is swimming ability related to morphological attributes of the larvae?

\section{MATERIALS AND METHODS}

Three species of reef fishes were examined: the ambon damselfish Pomacentrus amboinensis (Pomacentridae; Pomacentrinae), the coral cardinal Sphaeramia nematoptera (Apogonidae), and the anemonefish Amphiprion melanopus (Pomacentridae; Amphiprioninae). All were collected from the northern Great Barrier Reef. The species selected differed markedly in terms of their larval ecology. $P$. amboinensis and $S$. nematoptera have long larval durations of about 20 and $24 \mathrm{~d}$ respectively, whereas $A$. melanopus has a very short larval duration of approx. $9 \mathrm{~d}$. Adult brood stock were kept in >1000 l aquaria and were fed a diet of chopped pilchards, prawns and Ascetes twice a day. Rearing methods follow Job \& Bellwood (2000). Larvae were reared in $200 \mathrm{l}$ aquaria at 27.5 to $29^{\circ} \mathrm{C}$, under a 14:10 h light:dark photoperiod, throughout the study period. The alga Nannochloropsis sp. was used to green the water during the day. Larvae were fed $>52 \mu \mathrm{m}$-filtered, wild-caught plankton, supplemented occasionally by rotifers and Artemia sp., at prey densities of between 2 and 6 ind. $\mathrm{ml}^{-1}$.

Swimming experiments for older larvae were carried out using the technique and swimming flume described by Stobutzki \& Bellwood (1997). Two additional swimming channels were designed for use with younger larvae (Fig. 1). These channels operated at slower speeds (between 0 and $15 \mathrm{~cm} \mathrm{~s}^{-1}$ ) and had a much wider swimming area to minimise the area influenced by boundary layers. The swimming channels of the 2 chambers were $15 \mathrm{~cm}$ wide $\times 6.5 \mathrm{~cm}$ deep $\times 35 \mathrm{~cm}$ long and $10 \mathrm{~cm}$ wide $\times 5.5 \mathrm{~cm}$ deep $\times 30 \mathrm{~cm}$ long, for the 'slow' and 'medium' speeds, respectively. Both channels could be placed an aquaria with greened water so that there was no change in water quality between the experimental apparatus and the rearing tanks. Both swimming channels were calibrated using video and neutral-density particles.

Each batch of eggs from each species was raised from hatching through to settlement. Experiments were performed throughout the larval period, with sampling days depending on the species. The first swimming trial was conducted on Day 1, approx. $12 \mathrm{~h}$ after hatching. Three batches of each species were used for each swimming trial to allow for batch effects. 


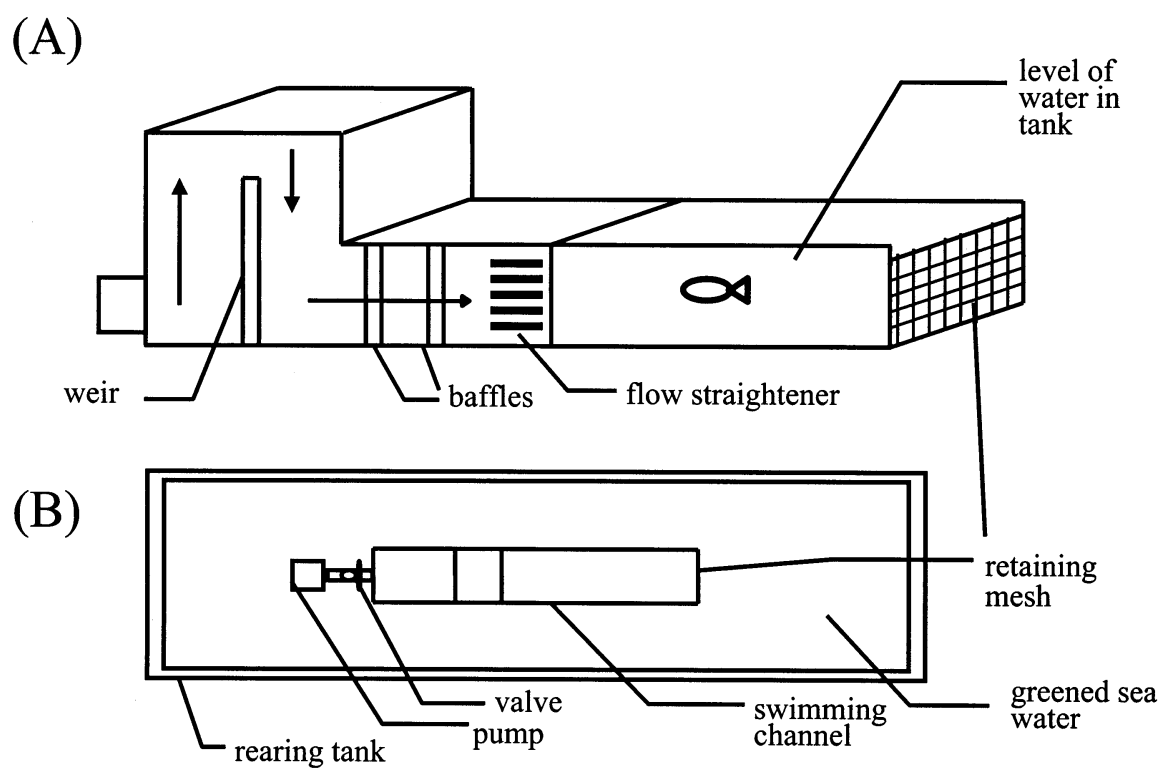

Fig. 1. Swimming channel for younger larvae. (A) Lateral view of apparatus; (B) top view of apparatus in experimental tank

At each experimental age, 8 to 12 fish were used from each batch for the swimming trials. The mean of these 8 to 12 fish was used for statistical analyses. In all experiments, larvae were transferred to the appropriate swimming chamber and allowed to acclimatise for 2 to $15 \mathrm{~min}$. Fish that exhibited symptoms of stress such as erratic swimming behaviour, lying on the bottom or in corners, or clinging to the sides or surface of the swimming channel were excluded from the experiments.

The critical swimming speed gives an indication of the maximum sustainable swimming speed of a fish, and involves increasing the flow rate against which the fish is swimming in gradual increments. In the present study, larvae were subjected to incremental increases in flow rates equivalent to approx. $3 \mathrm{BL}$ every $2 \mathrm{~min}$ until they could no longer maintain position for the full $2 \mathrm{~min}$. The equation used to calculate the critical swimming speed ( $\left.U_{\text {crit }}\right)$ of larvae followed Brett (1964):

$$
U_{\text {crit }}=U+\left(t / t_{\mathrm{i}} \times U_{\mathrm{i}}\right)
$$

where $U=$ penultimate speed, $U_{\mathrm{i}}=$ velocity increment ( $3 \mathrm{BL}), t=$ time swum in the final velocity increment, and $t_{\mathrm{i}}=$ set time interval for each velocity increment (2 $\mathrm{min})$.

Allometric studies have demonstrated that the highest level of activity, achieved at the top speed within any one gait, is size-dependent, and thus at any given absolute speed different-sized fish may not be at similar relative levels of exertion (Drucker 1996). In order to compare the sustained swimming abilities of larvae of different species at different ages, sustained swimming trial speeds were set as a multiple of body length. Fish were placed in the appropriate swimming channel and swam at a speed equivalent to approx. 11 body lengths (BL) per second until exhausted. Larvae were observed continuously for the first $5 \mathrm{~min}$, every $10 \mathrm{~min}$ for the first hour, and every 2 to $4 \mathrm{~h}$ thereafter. The total duration recorded represented of the swimming time up to the last occasion on which an individual was observed swimming. Actual swimming durations may be up to $4 \mathrm{~h}$ longer for the older larvae.

Fishes that had swum, or siblings of the same age, were anaesthetised in chilled water and then fixed in $10 \%$ buffered formalin. After 12 to $48 \mathrm{~h}$, larvae were transferred to $70 \%$ alcohol and stored. Measurements were taken of total length (from the tip of the caudal fin to the tip of the upper jaw), body depth (the height of the fish measured at the deepest region), body area (the entire area of the fish in lateral view excluding the fins) and total propulsive area (the area of the fish including the fins but excluding the head and gut region). Although larvae exhibit some degree of shrinkage (approx. 10\%), this varies among ages and parameters (Job \& Bellwood 1996). For consistency, all values are based on raw (non-corrected) measurements. The Reynolds numbers (Re) for the sustained swimming trials were calculated for the mean of each batch at each age using the formula: Re $=U \times L / v($ after Webb \& Weihs 1986), where $U=$ sustained swimming speed $\left(\mathrm{m} \mathrm{s}^{-1}\right), L=$ body depth $(\mathrm{m})$, and $v=$ kinematic viscosity of sea water $\left(1.03 \times 10^{-6}\right.$ $\left.\mathrm{m}^{2} \mathrm{~s}^{-1}\right)$. 
Scatterplots and regressions were used to investigate the relationship between swimming ability and age. Analyses were based on both age since hatching and developmental age. Developmental age provides a way of comparing larvae between species at similar ontogenetic stages and was calculated following Job \& Bellwood (2000): developmental age = total age/ total larval duration, where total age $=$ age of fish (days post-hatch) + egg duration and total larval duration = larval duration (days post-hatch) + egg duration.

Scatterplots and regressions were also used to describe the development of swimming ability with increasing size. To investigate the relationship between swimming ability and changes in the shape of larvae, measurements were standardised by dividing each variable by total length. Zero-order, as well as partial correlation coefficients were used to determine which of the relative morphological variables were most useful for modelling swimming ability. For all regressions, dummy variable analysis using cornerpoint parameterisation was used to determine if there were significant differences in either the slopes or intercepts for each species (Silk 1976). This technique involves comparing the sum of squares obtained for the most complex model (each species has different slopes and intercepts) with simpler models (2 or 3 species have the same slope and/or intercept) using $F$ tests. Where multiple $F$-tests were used, a Bonferroni correction was applied. The assumptions of all regressions were tested graphically, and data were $\log _{10^{-}}$ transformed when appropriate. In the case of sustained swimming time, transformation was unable to linearise the relationship with all of the parameters investigated. Consequently, statistical analyses based on the assumption of linearity were not used and the development of sustained swimming ability was described using scatterplots.

\section{RESULTS}

Critical swimming ability increased with age for all 3 species (Fig. 2A). Initially, critical swimming ability increased slowly with age, then improved rapidly for older stages, with the exception of Sphaeramia nematoptera, in which critical swimming ability increased steadily throughout development (Fig. 2A). At $12 \mathrm{~h}$ after hatching, all 3 species had some critical swimming ability, with mean critical swimming speeds ranging from $1.8 \mathrm{~cm} \mathrm{~s}^{-1}$ for $S$. nematoptera to $4.6 \mathrm{~cm} \mathrm{~s}^{-1}$ for Amphiprion melanopus (Table 1). The mean critical swimming speeds obtained just prior to settlement ranged from $10.9 \mathrm{~cm} \mathrm{~s}^{-1}$ for $S$. nematoptera to $30.3 \mathrm{~cm}$ $\mathrm{s}^{-1}$ for Pomacentrus amboinensis (Table 1).
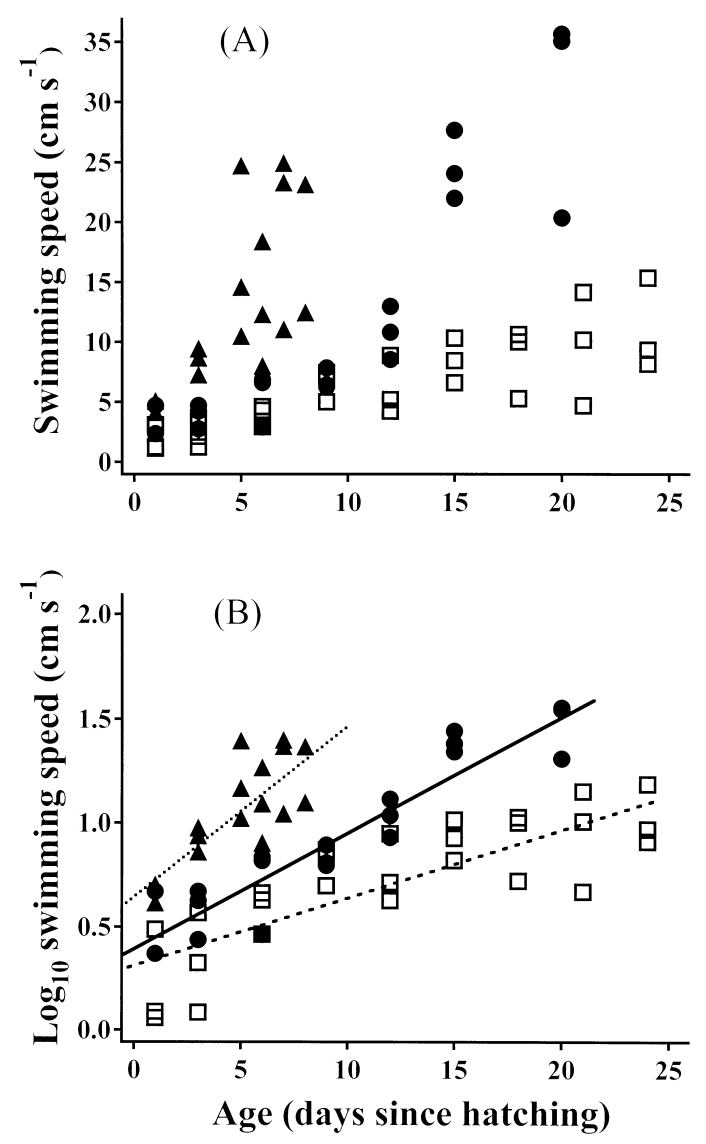

Fig. 2. Pomacentrus amboinensis (•), Sphaeramia nema-

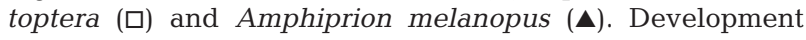
of critical swimming speed with age. (A) Raw values; (B) $\log _{10}$-transformed values

Table 1. Pomacentrus amboinensis, Sphaeramia nematoptera, Amphiprion melanopus. Mean and maximum critical swimming speed and sustained swimming time $12 \mathrm{~h}$ after hatching and at settlement. Values in parentheses $=\mathrm{SE}(\mathrm{n}=3$ batches of 8 to 12 fish)

\begin{tabular}{|c|c|c|c|c|}
\hline \multirow[t]{2}{*}{ Species } & \multicolumn{2}{|c|}{$\begin{array}{c}\text { Critical } \\
\text { speed }\left(\mathrm{cm} \mathrm{s}^{-1}\right)\end{array}$} & \multicolumn{2}{|c|}{$\begin{array}{c}\text { Sustained } \\
\text { swimming time (h) }\end{array}$} \\
\hline & Mean & Max. & Mean & Max. \\
\hline \multicolumn{5}{|l|}{ At hatching } \\
\hline P. amboinensis & $3.5(1.2)$ & 6.4 & $0.11(0.04)$ & 0.5 \\
\hline S. nematoptera & $1.8(0.6)$ & 4.4 & $0.02(0.02)$ & 0.2 \\
\hline A. melanopus & $4.6(0.2)$ & 8.2 & $0.26(0.12)$ & 1.1 \\
\hline \multicolumn{5}{|l|}{ At settlement } \\
\hline P. amboinensis & $30.3(5.0)$ & 48.1 & $90.4(31.9)$ & 234 \\
\hline S. nematoptera & $10.9(2.2)$ & 24.2 & $4.3(4.3)$ & 39.9 \\
\hline A. melanopus & $14.6(4.5)$ & 35.7 & $8.6(4.8)$ & 44.25 \\
\hline
\end{tabular}

The relationship between critical swimming ability and age differed significantly among the 3 species. In terms of critical swimming ability, Pomacentrus amboinensis and Amphiprion melanopus have a very 
similar developmental rate with age (Fig. 2B), with no significant difference between the slopes $\left(F_{3,60}=1.15\right.$, $\mathrm{p}=0.34)$. A. melanopus, however, hatches with significantly greater critical swimming abilities than the other 2 species $\left(F_{1,58}=218.1, \mathrm{p}<0.0001\right)$ (Fig. 2B). Sphaeramia nematoptera, although hatching at a similar state of development in terms of critical swimming ability as $P$. amboinensis $\left(F_{3,60}=0.15, \mathrm{p}=0.34\right)$, has a significantly slower rate for the development of swimming ability with age $\left(F_{1,58}=194.5, \mathrm{p}<0.0001\right)$, taking longer to reach much slower final speeds than $P$. amboinensis (Fig. 2B).

All 3 species hatched with very little sustained swimming abilities, and each developed this ability quite differently with age. Sphaeramia nematoptera had the poorest sustained swimming ability throughout development, exhibiting very little sustained swimming at any age (Fig. 3A). Pomacentrus amboinensis had the greatest sustained swimming ability, and this developed rapidly 12 to $15 \mathrm{~d}$ after hatching (Fig. 3A). Amphiprion melanopus had shorter sustained swimming times than $P$. amboinensis, with a mean of $8.6 \mathrm{~h}$ at the oldest age compared to $90.4 \mathrm{~h}$ for $P$. amboinensis (Table 1). A. melanopus, however, did display the earliest development of swimming ability, with some
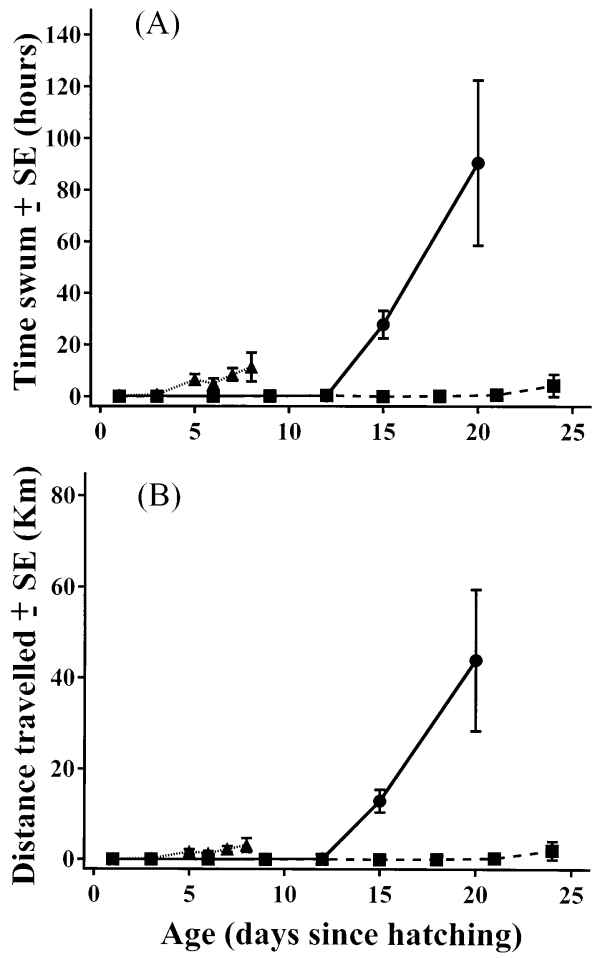

Fig. 3. Pomacentrus amboinensis (•), Sphaeramia nematoptera (₫) and Amphiprion melanopus (⿶). Development of sustained swimming ability with age. (A) Sustained swimming time in hours; (B) equivalent distance travelled degree of sustained swimming ability between Days 3 and 5 after hatching (Fig. 3A). All 3 species had considerably higher maximum swimming times, and the mean values displayed here are clearly a conservative estimate of the potential swimming abilities of the 3 species (Table 1). Although most sustained swimming values for $S$. nematoptera were near zero, the maximum values obtained indicated that at $24 \mathrm{~d}$ some individuals were able to swim for up $39.9 \mathrm{~h}$ (Table 1). A similar pattern is obtained if the equivalent distance that the larvae have travelled is calculated, based on the speeds at each age and the overall time swum (Fig. 3B). All 3 species swam very short distances immediately after hatching. A. melanopus was only able to swim very short distances throughout the larval period, although this species was able to swim around $4 \mathrm{~km}$ just $5 \mathrm{~d}$ after hatching (Fig. 3B). In contrast, $P$. amboinensis exhibited no sustained swimming abilities until $15 \mathrm{~d}$ after hatching. Although developing sustained swimming ability at a much slower rate, $P$. amboinensis was capable of swimming $12 \mathrm{~km}$ at $15 \mathrm{~d}$ post-hatch and $40 \mathrm{~km}$ at $20 \mathrm{~d}$ post-hatch (Fig. 3B). $S$. nematoptera, on average, was able to swim only very short distances throughout the larval period (Fig. 3B).

Critical swimming ability increased exponentially with developmental age in all 3 species (Fig. 4A). There was no significant differences in the slopes for all species, or in the intercepts for Sphaeramia nematoptera and Amphiprion melanopus $\left(F_{3,61}=2.17, \mathrm{p}=\right.$ $0.10)$, indicating that all 3 species develop critical swimming abilities at a similar rate in terms of developmental age. Although Pomacentrus amboinensis was found to have a significantly different intercept $\left(F_{3,61}=4.9, \mathrm{p}=0.004\right)$, this difference was much less than that seen when the development of critical swimming ability is compared using age since hatching.

The 3 species exhibited different sustained swimming abilities, even at similar developmental ages. Pomacentrus amboinensis had the greatest sustained swimming ability, followed by Amphiprion melanopus and then Sphaeramia nematoptera. The sustained swimming ability of $S$. nematoptera was very poor at all ontogenetic stages (Fig. 4B). Although the magnitudes of sustained swimming ability were different for P. amboinensis and A. melanopus, these species developed sustained swimming abilities at a similar stage of ontogenetic development (Fig. 4B), in marked contrast to the onset of abilities in terms of age since hatching (Fig. 3A).

Critical swimming speed increased proportionally with total length for all 3 species, but the rate of development and the values of critical swimming ability for a given length differed among species. Amphiprion melanopus increased swimming ability with increasing length at a significantly faster rate than the other 
2 species $\left(F_{1,58}=10.09, \mathrm{p}<0.001\right)$ (Fig. 5B). Pomacentrus amboinensis and Sphaeramia nematoptera developed swimming ability at a similar rate with increasing length (Fig. 5B), with no detectable difference between these rates $\left(F_{1,58}=0.37, \mathrm{p}=0.54\right)$. However, there was a significant difference in the intercepts $\left(F_{2,59}=11.62, \mathrm{p}<0.0001\right)$, with $P$. amboinensis having considerably better swimming abilities for a given length than S. nematoptera (Fig. 5B). Sustained swimming time also increased with increasing total body length, but only for $P$. amboinensis and A. melanopus. $S$. nematoptera exhibited very little sustained swimming ability at any length (Fig. 6). P. amboinensis developed sustained swimming ability at a body length of around $11.5 \mathrm{~mm}$, with shorter larvae exhibiting very little sustained swimming ability (Fig. 6). A. melanopus appeared to develop sustained swimming abilities smoothly with increasing length, and showed some sustained swimming abilities even at a length of only 5 or $6 \mathrm{~mm}$, which is at a considerably shorter body length than $P$. amboinensis (Fig. 6).
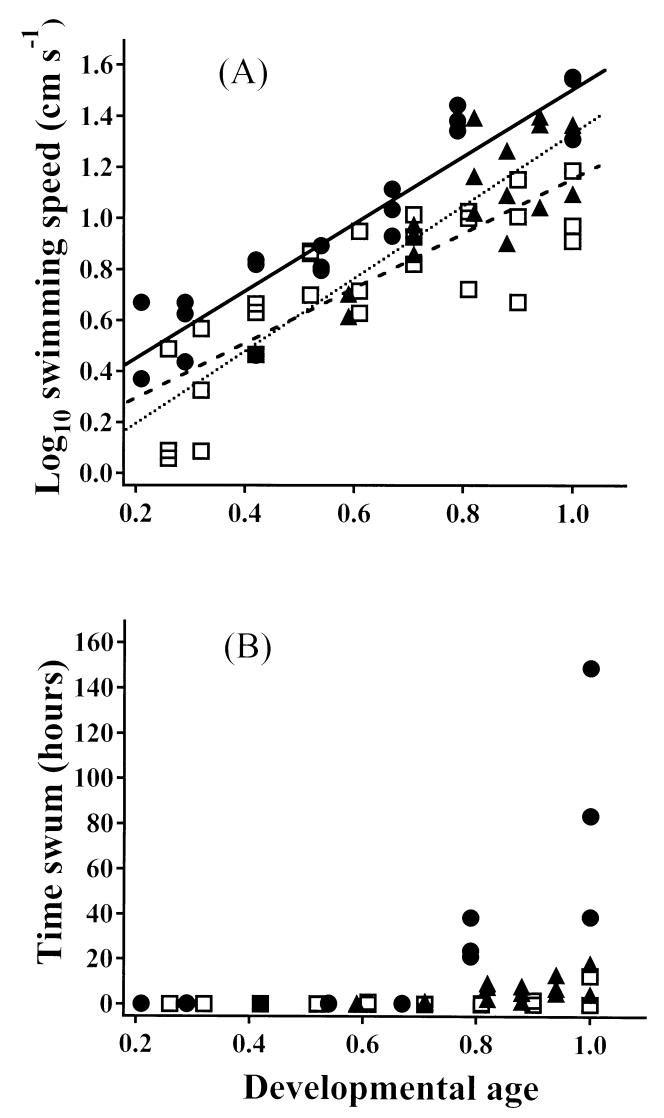

Fig. 4. Pomacentrus amboinensis (•), Sphaeramia nematoptera ( $\square$ ) and Amphiprion melanopus (४). Swimming ability vs developmental age. (A) Critical swimming speed; (B) sustained swimming time
Partial correlation coefficients for the 3 morphological variables indicated that for sustained and critical swimming ability, relative propulsive area described the greatest amount of unique variation in nearly all cases (Table 2). A plot of relative propulsive area against critical swimming ability suggested a similar relationship for all 3 species (Fig. 7A). Statistical analysis indicated that there was only a marginal difference between the slope for Pomacentrus amboinensis and the other 2 species $\left(F_{4,61}=2.71, \mathrm{p}=0.04\right)$. Overall, critical swimming ability increased similarly with increasing relative propulsive area for all species. While there was no simple linear relationship between sustained swimming time and relative propulsive area, there was a similar pattern for all 3 species (Fig. 7B). There appeared to be a common value of propulsive area relative to length at which sustained swimming ability first occurs for all 3 species. The Reynolds numbers experienced by larvae throughout their developed increased steadily from hatching through to settlement. For all species, a significant increase in sus-
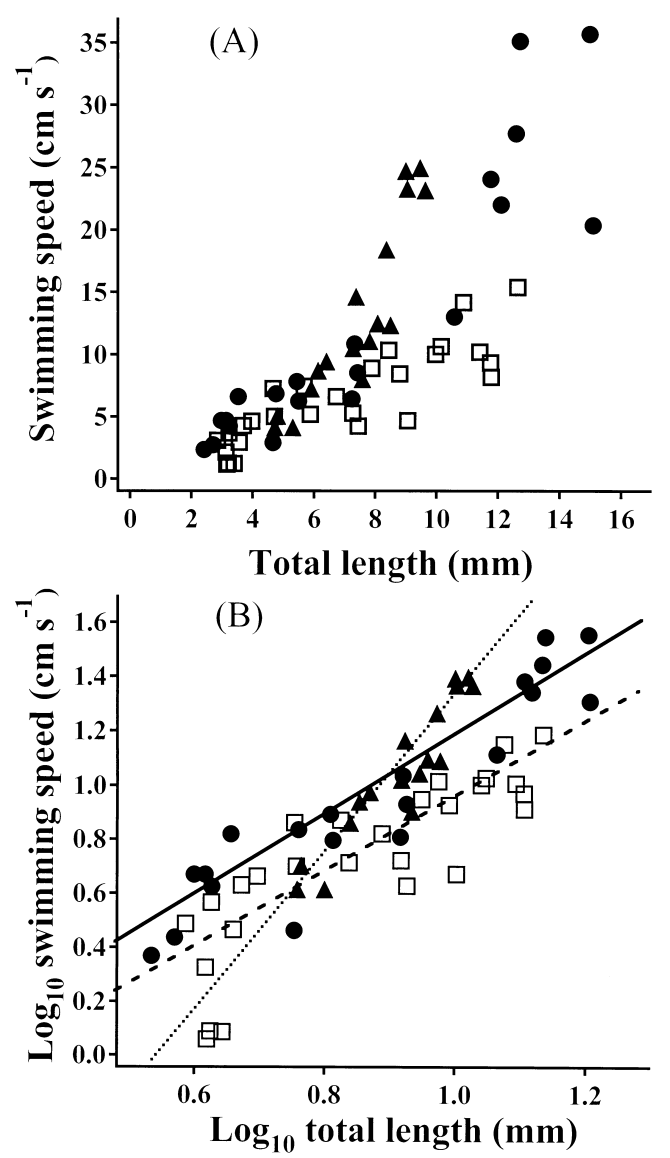

Fig. 5. Pomacentrus amboinensis (•), Sphaeramia nema-

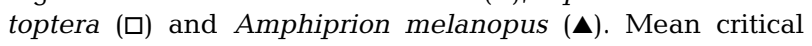
swimming speed vs total length. (A) Raw values; (B) $\log _{10^{-}}$ transformed values 
tained swimming ability was not recorded at Re values below 500 (Fig. 8). However, Re values at the time when sustained swimming ability first occurs differed for each species, with Amphiprion melanopus exhibit-
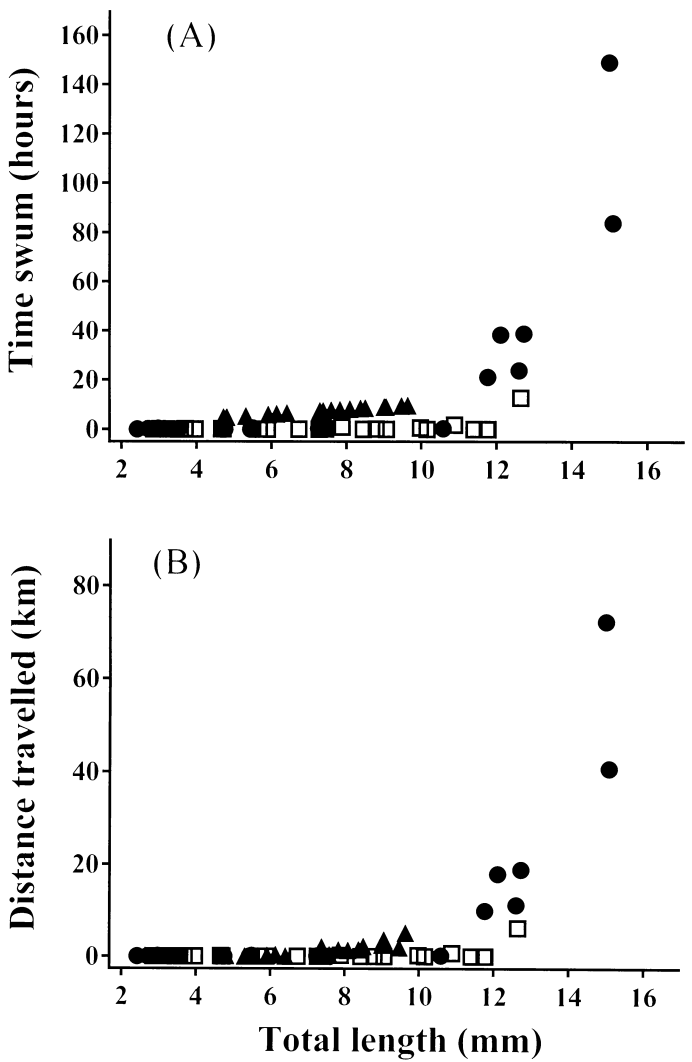

Fig. 6. Pomacentrus amboinensis (•), Sphaeramia nema-

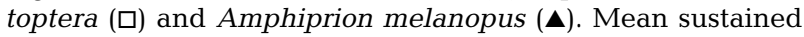
swimming ability vs total length. (A) Sustained swimming time in hours; (B) equivalent distance travelled

Table 2. Pomacentrus amboinensis, Sphaeramia nematoptera, Amphiprion melanopus. Partial correlation coefficients for multiple regression between critical swimming speed and sustained swimming time versus body area, body depth, and propulsive area. All variables were standardised relative to total length. Values in bold indicate morphological variables with the highest partial correlation coefficients for each species. Data were $\log _{10}$-transformed prior to analysis

\begin{tabular}{|lrrc|}
\hline Species & $\begin{array}{r}\text { Body } \\
\text { area }\end{array}$ & $\begin{array}{r}\text { Body } \\
\text { depth }\end{array}$ & $\begin{array}{c}\text { Propulsive } \\
\text { area }\end{array}$ \\
\hline Critical swimming speed & & & \\
P. amboinensis & 0.22 & -0.07 & $\mathbf{0 . 4 4}$ \\
S. nematoptera & $\mathbf{0 . 6 7}$ & -0.45 & 0.17 \\
A. melanopus & 0.09 & 0.13 & $\mathbf{0 . 7 3}$ \\
Sustained swimming time & & & \\
P. amboinensis & -0.10 & -0.08 & $\mathbf{0 . 4 6}$ \\
S. nematoptera & -0.05 & 0.08 & $\mathbf{0 . 2 1}$ \\
A. melanopus & -0.32 & -0.32 & $\mathbf{0 . 7 2}$ \\
& & & \\
& & & \\
& & &
\end{tabular}

ing sustained swimming at Re values considerably lower than those for P. amboinensis (Fig. 8).

\section{DISCUSSION}

The 2 measures of swimming ability, critical and sustained, provide different estimates of swimming performance. Critical swimming speed provides a maximum performance measure of the speeds at which fishes can swim, as well as a means of directly comparing the development of swimming capabilities among species. In Pomacentrus amboinensis, Sphaeramia nematoptera, and Amphiprion melanopus, critical swimming speeds increased with age, size, developmental age and relative propulsive area. The development of critical swimming ability is probably based largely on the development of muscles and other features related to locomotion, as well as the ability to use readily available energy reserves. The biological implications of critical swimming speeds relate to the ability of the larvae to cover short distances $(<500 \mathrm{~m})$ at
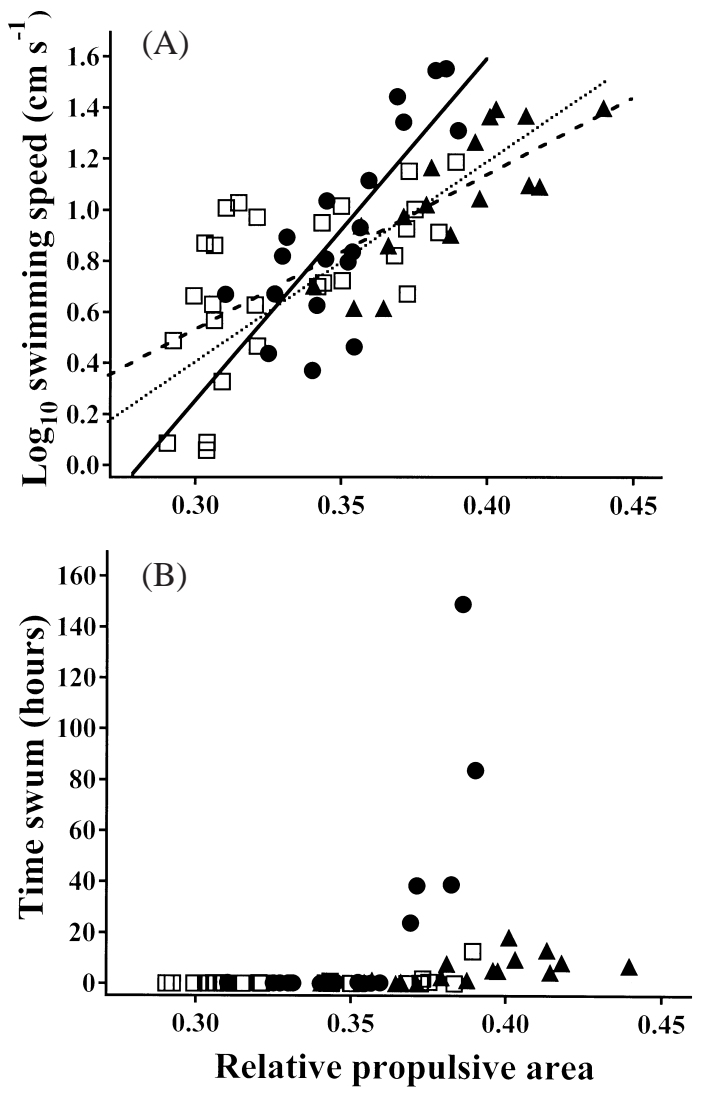

Fig. 7. Pomacentrus amboinensis (•), Sphaeramia nematoptera ( $\square$ ) and Amphiprion melanopus ( $\mathbf{(})$. Swimming ability vs relative propulsive area. (A) Critical swimming speed;

(B) sustained swimming time 


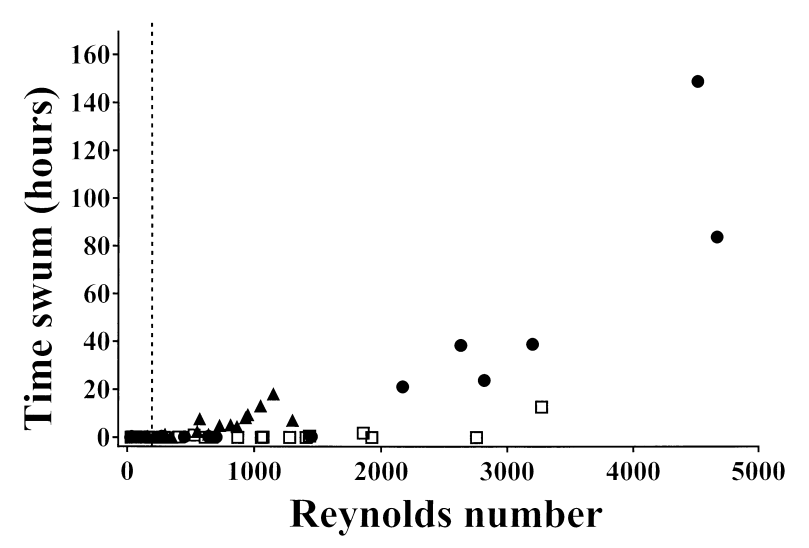

Fig. 8. Pomacentrus amboinensis (•), Sphaeramia nematoptera ( $\square$ ) and Amphiprion melanopus (४). Sustained swimming time vs Reynolds number. Dotted line: $R e=200$

high speeds (up to $48 \mathrm{~cm} \mathrm{~s}^{-1}$ ), over short time scales (<30 min). These abilities may be important in terms of the potential for larvae to move between locations on a small scale (e.g. within slicks), to vertically migrate to access different current regimes or prey, to move away from reefs at hatching, or to move between habitats at settlement. High abundances of larval fishes have been found in areas of internal waves, slicks and fronts, and this may be due to active migration of larvae to these areas, possibly because of increased food availability (Franks 1992). Critical swimming capabilities of larval fishes are likely to be important for such small-scale movement, and possibly in the modification of broad-scale dispersal patterns via vertical migration (see Job \& Bellwood 2000).

In contrast to critical swimming speed, sustained swimming increased very differently among the species with both age and size, suggesting that the factors involved are more complex than those required for the development of critical swimming abilities. The development of sustained swimming ability varied from no development at all in Sphaeramia nematoptera, a fairly smooth transition in Amphiprion melanopus, to a rapid jump in Pomacentrus amboinensis. The development of sustained swimming may be dependent upon both physiological and behavioural changes during ontogeny. Sustained swimming experiments provide a measure of the long-term swimming abilities of larvae. However, this method may underestimate the swimming capabilities of larvae in the field (Stobutzki \& Bellwood 1997). In the trials, larvae were not permitted to feed or rest and were unable to select their optimal swimming speeds. Leis \& Carson-Ewart (1998) have observed larvae feeding whilst maintaining such high speeds. Given food, rest and the ability to select preferred swimming speeds, the swimming times might have been much higher. Although there is a great deal of variation among species, this method provides a maximum performance measure of the sustained swimming capabilities of larvae, which may reflect relative abilities of larvae to modify dispersal patterns in the field.

\section{Among-species differences - Is it possible to predict swimming ability across different species?}

The development of both critical swimming speeds and sustained swimming times of larvae showed clear differences among the 3 species. Comparable differences in the swimming ability among taxa have been reported by other authors (Leis et al. 1996, Stobutzki \& Bellwood 1997, Stobutzki 1998), and have been attributed to differences in developmental stage and morphology at the end of the pelagic stage (Stobutzki \& Bellwood 1997). The differences observed in the present study appear to reflect the larval strategies of the 3 species. They hatch at varying stages of development and go through the larval period at different rates. However, if one considers the development of critical swimming speeds in terms of developmental age, which provides a way of comparing the species at similar stages of ontogenetic development (Job \& Bellwood 2000), critical swimming ability increased similarly for all 3 species. Interestingly, Job \& Bellwood describe a comparable pattern in the development of visual abilities of these species.

The differences between the swimming abilities of the 3 species can also be explained by the morphology of the larvae. All 3 species display a similar pattern, with critical swimming speeds increasing with increasing relative propulsive area. Other studies have reported that various measures of body muscle or propulsive area may, along with length, explain differences in swimming abilities. These include differences in the percentage of muscle relative to other body tissue (Bainbridge 1960) and the sagittal area of the body musculature (Ryland 1962). Furthermore, the length of the body that is undulated is known to vary among species (Jayne \& Lauder 1995) and may explain differences in swimming ability. Propulsive area, as defined in the present study, approximates the area of the fish that can be undulated during swimming. This variable appears to give a good indication of the swimming capabilities of larval fishes, probably because it provides a measure of the development of the functional region of the fish used for swimming. If the relationship between relative propulsive area and swimming ability is similar in a number of additional species, it is possible that this variable may prove useful for general predictions of the swimming capabilities of larval fishes, including taxa which are difficult to rear in captivity. 
Reynolds numbers (Re) have also been identified as an important factor in the development of swimming abilities in larval fishes (Webb \& Weihs 1986). Re values give a measure of the ratio of forces arising from inertial and viscous effects as a fish moves through water. At small Re values $(<200)$, the interaction between the fish and the water changes so that swimming becomes energetically expensive. Considering that all the species in this study did not develop sustained swimming until they had attained Re values considerably larger than 200, this may be a constraining factor only in the development of sustained swimming in very young larvae. It is unlikely that Re values are important for the development of sustained swimming ability, particularly as all 3 species developed sustained swimming at very different values of Re.

\section{Implications for dispersal}

The 3 species investigated in this study displayed quite different patterns of development of swimming ability. Although some species, such as Sphaeramia nematoptera, appear to exhibit very little swimming ability, and may be considered 'passive', others are clearly capable of exerting considerable influence over their dispersal patterns. The 2 species that did exhibit sustained swimming, however, developed these abilities considerably faster than expected. Critical swimming abilities for these species also developed rapidly. Pomacentrus amboinensis rapidly develops excellent sustained swimming abilities somewhere between Days 12 and 15 after hatching. Thus, for nearly half of the larval phase, this species is capable of significantly influencing its dispersal patterns by active swimming. This changes the potential distance that larvae of this species are able to cover before settlement from about $34 \mathrm{~km}$ (based on the ability to swim for the last $2 \mathrm{~d}$ of the pelagic period) to $93 \mathrm{~km}$ (based on the ability to swim for the last $6 \mathrm{~d}$ of the pelagic period, at a speed of $13.5 \mathrm{~cm} \mathrm{~s}^{-1}$ ). These values may be considerably greater if we further assume that larvae are able to delay metamorphosis until they find a suitable settlement site (see McCormick 1999) and that they are able to feed whilst swimming (see Leis \& Carson-Ewart 1998). Amphiprion melanopus also develops sustained swimming abilities earlier than expected, but differs from $P$. amboinensis in increasing its sustained swimming ability gradually with age. A. melanopus was capable of some sustained swimming starting between 3 and $5 \mathrm{~d}$ after hatching, and this ability increased consistently throughout the larval period. The development of significant swimming abilities relatively soon after hatching, along with well-developed sensory systems (Job \& Bellwood 2000), and a very short larval duration suggests that there is a high potential for this species to remain near to the natal reef. Preliminary results for Amphiprion percula (Fisher unpubl. data) indicated that the rapid development of swimming ability observed in A. melanopus may be common to other anemonefish species. These findings are consistent with the observation that there appears to be a high degree of genetic differentiation between some populations of anemonefish, an indication of limited dispersal (Bell et al. 1982). Job \& Bellwood (2000) suggest that the precocious development in anemonefishes may be related to low post-settlement mortality rates and the need for well-developed sensory systems rather than size at settlement.

In at least 2 of the 3 species investigated, swimming abilities develop at an early enough age to substantially influence their dispersal patterns. If they use their swimming capabilities to modify dispersal, genetic evidence suggests that they are using them to retard rather than enhance dispersal (Doherty et al. 1995). There is considerable evidence from hydrodynamic studies suggesting that young larvae will not necessarily be transported very far from reefs (Black et al. 1991, Black 1993), particularly in the summer months (Frith et al. 1986). Local retention, along with the early development of swimming ability in some demersal-spawning reef fishes, suggests that many populations of reef fishes may have a significant potential for self-seeding ${ }^{1}$.

The 3 species investigated in this study were all demersal brooders. Fish larvae which hatch from demersal eggs are more developed in terms of their sensory and swimming abilities than larvae which hatch from pelagic eggs (Kobayashi 1989, Leis 1991a), and are more likely to be able to remain near the reef of origin (Leis 1991b, Brogan 1994). Apparently anomalous distribution patterns have been observed in larvae with demersal eggs, with studies often reporting higher abundances near to shore (Leis 1986, Kingsford \& Choat 1989). This may indicate that these larvae are using the early development of their motor skills to influence their dispersal patterns or that they are very adept at using currents to reduce advection. It is yet to be determined how swimming ability develops in pelagic spawners, but it is likely to follow a period of relative passivity during early development.

Larval fishes exhibit excellent swimming abilities that develop, especially for critical swimming ability, early in larval life and improve consistently throughout

\footnotetext{
${ }^{1}$ Since submission of this paper 3 articles have been published highlighting the potential for self seeding in reef fishes. See Jones et al. (Nature 402:802-804, 1999), Swearer et al. (Nature 402:799-802, 1999) and Cowen et al. (Science 287: $857-860,2000)$
} 
the larval period. However, swimming is only one aspect of larval biology that will enable them to exhibit behaviour potentially important in influencing dispersal. Job \& Bellwood (2000) indicate that larvae of the study species are able to feed at considerable depths (50 to $200 \mathrm{~m}$ ) even from an early age, and that this may provide access to a range of current regimes. The combination of prolonged access to deep water and the early development of swimming abilities suggest that even the youngest larvae of these taxa have considerable potential to actively modify their dispersal and reduce advection from reefs. Clearly, the potential of larvae to modify their dispersal is not restricted to the last few days of the pelagic period.

The present study has demonstrated that there are great differences in the development of swimming ability in the larvae of reef fishes and that these differences are apparent shortly after hatching. In order to fully understand the potential capabilities of larvae in modifying their dispersal, the whole of the larval period must be considered. Information based solely on the swimming abilities of older stages may be misleading because it does not take into account how quickly or slowly their relative swimming abilities develop during the pelagic period. Overall, it appears that there is no such thing as a typical fish larva at any stage and that some species of fish have considerably more potential for influencing their dispersal than others.

Acknowledgements. We thank I. Stobutzki for use of her swimming channel; the staff of the James Cook University Research Aquarium and D. Ross for technical support; R. Alford, M. Sheaves, M. Blows and R. Brooks for statistical advice; and R. Alford and R. Rowe for use of technical equipment. This paper was improved as a result of the comments of J. Leis and M. McCormick. This research was supported by an augmentative research grant from the CRC Reef Research Centre (R.F.) and the Australia Research Council (D.R.B).

\section{LITERATURE CITED}

Bainbridge R (1960) Speed and stamina in 3 fish. J Exp Biol 370:129-153

Bell LJ, Moyer JT, Numachi K (1982) Morphological and genetic variation in Japanese populations of the anemonefish Amphiprion clarkii. Mar Biol 72:99-108

Bellwood DR, Leis JM, Stobutzki IC (1998) Fishery and reef management. Science 279:2021-2022

Black KP (1993) The relative importance of local retention and inter-reef dispersal of neutrally buoyant material on coral reefs. Coral Reefs 12:43-53

Black KP, Moran PJ, Hammond LS (1991) Numerical models show coral reefs can be self-seeding. Mar Ecol Prog Ser 74:1-11

Booth DJ, Baretta GA (1994) Seasonal recruitment, habitat associations and survival of pomacentrid reef fish in the US Virgin islands. Coral Reefs 13:81-89
Brett JR (1964) The respiratory metabolism and swimming performance of young sockeye salmon. J Fish Res Board Can 21:1183-1226

Brogan MW (1994) Distribution and retention of larval fishes near reefs in the Gulf of California. Mar Ecol Prog Ser 115: $1-13$

Choat JH, Doherty PJ, Kerrigan BA, Leis JM (1993) A comparison of towed nets, purse seines and light aggregation devices for sampling larvae and pelagic juveniles of coral reef fishes. Fish Bull US 91:195-209

Cowen RK, Hare JA, Fahay MP (1993) Beyond hydrography can physical processes explain larval fish assemblages within the Middle Atlantic Bight. Bull Mar Sci 53:567-587

Doherty PJ (1991) Spatial and temporal patterns in recruitment. In: Sale PF (ed) The ecology of fishes on coral reefs. Academic Press, San Diego, p 261-293

Doherty PJ, Planes S, Mather P (1995) Gene flow and larval duration in seven species of fish from the Great Barrier Reef. Ecology 76:2373-2391

Drucker EG (1996) The use of gait transition speed in comparative studies of fish locomotion. Am Zool 36:555-566

Franks PJS (1992) Sink or swim. Accumulation of biomass at fronts. Mar Ecol Prog Ser 82:1-12

Frith CA, Leis JM, Goldman B (1986) Currents in the Lizard Island region of the Great Barrier Reef Lagoon and their relevance to potential movements of larvae. Coral Reefs 5: 81-92

Jayne BC, Lauder GV (1995) Speed effects on midline kinematics during steady undulatory swimming of large mouth bass, Micropterus salmoides. J Exp Biol 198:585-602

Job S, Bellwood DR (1996) Visual acuity and feeding in larval Premnas biaculeatus. J Fish Biol 48:952-963

Job S, Bellwood DR (2000) Light sensitivity in larval fishes: implications for vertical zonation in the pelagic zone. Limnol Oceanogr 45:362-371

Kingsford MJ, Choat JH (1989) Horizontal distribution patterns of presettlement reef fish: are they influenced by the proximity of reefs? Mar Biol 101:285-297

Kobayashi DR (1989) Fine-scale distribution of larval fishes: patterns and processes adjacent to coral reefs in Kaneohe Bay, Hawaii. Mar Biol 100:285-293

Leis JM (1986) Vertical and horizontal distribution of fish larvae near coral reefs at Lizard Island, Great Barrier Reef. Mar Biol 90:505-516

Leis JM (1991a) The pelagic stage of reef fishes: the larval biology of coral reefs. In: Sale PF (ed) The ecology of fishes on coral reefs. Academic Press, San Diego, p 183-229

Leis JM (1991b) Vertical distribution of fish larvae in the Great Barrier Reef Lagoon, Australia. Mar Biol 109: 157-166

Leis JM, Carson-Ewart BM (1997) In situ swimming speeds of the late pelagic larvae of some Indo-Pacific coral-reef fishes. Mar Ecol Prog Ser 159:165-174

Leis JM, Carson-Ewart BM (1998) Complex behaviour by coral-reef fish larvae in open-water and near-reef pelagic environments. Environ Biol Fish 53:259-266

Leis JM, Stobutzki IC (1997) Swimming performance of late pelagic larvae of coral-reef fishes: in situ and laboratory-based measurements. Proc Indo-Pac Fish Conf 5: $575-583$

Leis JM, Sweatman HPA, Reader SE (1996) What the pelagic stages of coral reef fishes are doing out in blue water: daytime field observations of larval behavioural capabilities. Mar Freshw Res 47:401-411

McCormick M (1999) Delayed metamorphosis of a tropical reef fish (Acanthurus triostegus): a field experiment. Mar Ecol Prog Ser 176:25-38 
Roberts CM (1997) Connectivity and management of Caribbean coral reefs. Science 278:1454-1457

Roberts CM (1998) Fishery and reef management. Science 279:2021-2022

Ryland JS (1962) The swimming speeds of plaice larvae. J Exp Biol 40:285-299

Sale PF, Cowen RK (1998) Fishery and reef management. Science 279:2021-2022

Silk J (1976) A comparison of regression lines using dummy variable analysis: models and examples of the bivariate case. University of Reading

Stobutzki IC (1998) Interspecific variation in sustained swimming ability of late pelagic stage reef fish from two families (Pomacentridae and Chaetodontidae). Coral Reefs 17: 111-119

Stobutzki IC, Bellwood DR (1994) An analysis of the critical

Editorial responsibility: John Austin (Assistant Editor),

Oldendorf/Luhe, Germany swimming abilities of pre- and post-settlement coral reef fishes. J Exp Mar Biol Ecol 175:275-286

Stobutzki IC, Bellwood DR (1997) Sustained swimming abilities of the late pelagic stages of coral reef fishes. Mar Ecol Prog Ser 149:35-41

Webb PW, Weihs D (1986) Functional locomotor morphology of early life history stages of fishes. Tran Am Fish Soc 115: $115-127$

Williams DMcB, Wolanski E, Andrews JC (1984) Transport mechanisms and their potential movement of planktonic larvae in the central region of the Great Barrier Reef. Coral Reefs 3:229-236

Wolanski E, Doherty P, Carleton J (1997) Directional swimming of fish larvae determines connectivity of fish populations on the Great Barrier Reef. Naturwissenchaften 84: $262-268$

Submitted: November 2, 1999; Accepted: February 15, 2000 Proofs received from author(s): August 3, 2000 